\title{
ADINKRA: CONSTRUÇÃO E APLICAÇÃO DE OFICINA GEOGRÁFICA NA ESCOLA
}

\author{
Andréa Rabelo Marcelino ${ }^{1}$ \\ Mari Helen Weber Voss ${ }^{2}$ \\ Miriane Buss Roecker ${ }^{3}$
}

\section{INTRODUÇÃO}

O presente trabalho é um relato de experiência realizado no Sub Projeto da disciplina de Geografia, Programa Institucional de Bolsa de Iniciação à Docência (PIBID), com a intenção de compartilhar as diferentes culturas existentes no continente africano. As atividades foram realizadas, durante uma oficina trabalhada no Dia da Consciência Negra em duas escolas de Ensino Fundamental II e Ensino Médio do município de Criciúma/SC.

Para a realização deste trabalho, se fez necessário discutir em grupos, pesquisar sobre o tema, planejar as ações, para posteriormente aplicar a oficina com os alunos em ambas as escolas.

O trabalho teve como objetivo conhecer um pouco mais sobre a cultura negra e/ou africana, desmistificando o preconceito sobre ela, utilizandose de carimbos (Adinkra).

\section{METODOLOGIA}

No subprojeto de Geografia, Programa Institucional de Bolsa de Iniciação à Docência (PIBID), no qual estavam escritas duas escolas, sendo uma da rede estadual de ensino, e outra municipal, localizadas no município de Criciúma/SC, encontrava-se no planejamento escolar das duas escolas a data

\footnotetext{
${ }^{1}$ Universidade do Extremo Sul Catarinense - UNESC, graduada em Geografia - Licenciatura e Bacharel, Pedagogia (UDESC). Especialista em Didática e Metodologia do Ensino Superior (UNESC). Docente dos cursos de Geografia e Pedagogia (UNESC). armarcelino@unesc.net ${ }^{2}$ Universidade do Extremo Sul Catarinense - UNESC, Graduanda do curso de Geografia Licenciatura. Bolsista do Programa do PIBID. marihhelen@hotmail.com

${ }^{3}$ Universidade do Extremo Sul Catarinense - UNESC, Graduanda do curso de Geografia Licenciatura. Bolsista do Programa do PIBID.miribroecker@hotmail.com
} 
do dia 20 de novembro, cujo dia é celebrado o Dia da Consciência Negra, no Brasil, simultaneamente o assunto trabalhado e discutido dentro das salas de aulas pelos professores das escolas inseridas ao subprojeto, era o continente africano. Trazendo então a oficina como uma didática e complementação do conteúdo levantado. A partir deste conhecimento deu-se início ao planejamento de atividades que visassem à diversidade da cultura africana. Segundo Passini (2007), o planejamento enquanto conteúdo é essencial para o bom desenvolvimento das atividades projetadas, e a falta deste, pode implicar 0 fracasso das atividades ministradas em sala de aula.

As pesquisas teóricas foram realizadas dentro das reuniões do subprojeto com a orientação dos professores das escolas, e da coordenadora, onde foram pensadas e produzidas as oficinas com temas diferenciados, mas todos voltados para a cultura africana. Tendo como parceiros de trabalhos os colegas pibidianos que ofertaram outras oficinas como exemplo uma oficina de contos, máscaras, jogos, exposição de imagens, e o "Adinkra" a qual se refere 0 artigo.

Buscamos utilizar materiais de fácil acesso para a realização da oficina. Foram reproduzidos os carimbos esculpidos no isopor, utilizando alguns dos símbolos pesquisados, desenhados não fielmente a tradição, mas que não deixasse de transmitir como era a cultura local. Dentre as cores oficiais dos carimbos se encontrava o preto, onde foi utilizado o guache desta cor, para que os alunos carimbassem as folhas de papel de forma representativa da cultura. Estampados em tecidos de TNT alguns símbolos, com os carimbos produzidos. Sendo expostos aos alunos, para que pudessem visualizar algo próximo de como eram os tecidos usados pelo povo desta localidade.

\section{RESULTADOS E DISCUSSÃO}

Em primeiro plano realizamos pesquisas para obter propriedade da cultura africana, escolhemos abordar a tradição que se espalha pelos territórios de Gana e Costa do Marfim, localizados no continente africano. A fim de "[...] selecionar o material necessário e as tarefas a serem executadas e repensar o plano diante de novas situações." (PASSINI, 2007). 
A cultura escolhida a trabalhar na oficina foi do povo de Akan, que trabalhava com a tecelagem de tecidos, destacando o "Adinkra". Um pano tradicional carimbado com ervas naturais, caracterizado por símbolos que transmitiam sabedoria local, e eram utilizados como vestimentas ou item decorativo. A partir dessas informações foi criada uma oficina, que conforme Callai et al. 1986, os alunos desenvolvem habilidades de aquisição através da oportunidade de observar, buscar respostas, elaborar e criar, o que os estimula perante o assunto proposto. Sendo estabelecido então como nome da oficina "ADINKRA, a arte dos carimbos".

Para que os alunos pudessem observar e compreender com maior visibilidade foi exposto algumas imagens de pessoas que utilizavam os tecidos como vestimentas, e de tecidos originais fabricados pelo povo local, com a intenção de atrair o interesse dos alunos, e para junção visual e auditiva, de uma breve explicação narrada. Como proposta de "[...] estimular o pensamento, o raciocínio, oportunizando a construção ativa dos conhecimentos através de um processo que parte da ação e encaminha-se à reflexão e à descoberta pelos alunos." (CALLAI, et al., 1986).

Dentro da oficina se disponibilizava os carimbos fabricados por nós bolsistas, juntamente com a tinta guache e folhas de papéis reciclados, para que os participantes da oficina criassem estampas a modo representativo de acordo com a cultura abordada.

Representando com a junção desses materiais, como recurso didático, a oportunidade de desenvolver valores e atitudes que se pretende trabalhar, como as diversidades existentes no mundo todo. Nesse momento trabalhando a diversidade cultural africana, trazendo "[...] como fator de informação e de formação voltada para a valorização dos descendentes [...]" (SECRETARIA DE EDUCAÇÃO FUNDAMENTAL, 1998, p.).

Como objetivo, segundo a Secretaria de Educação Fundamental (1998), um dos valores a ser reconhecido para a sustentabilidade social é de grande importância a conservação da diversidade dos tipos de sociedades, e de culturas.

Visando também como objetivo, a citação do livro Parâmetros Curriculares Nacionais: 
Toda a riqueza de soluções, de expressões culturais, de concepções de mundo, de vida em sociedade presentes nos milhares de povos contemporâneos, bem como em suas histórias, constitui-se igualmente num patrimônio que interessa a toda a humanidade conservar. Não no sentido de congelar, estancar. Mas no sentido de valorizar, respeitar e permitir a continuidade do processo históricocultural de cada povo, em vez de aculturá-lo, impondo-lhes condições de vida que exijam o abandono dos meios de subsistência e de produção cultural que thes são próprios. [...] todos os grupos de diferentes procedências que enriquecem a formação ética e cultural, devem ter seu espaço de manifestação garantido e sua dignidade e seu amor próprio resgatados quando em situação de desapreço ou discriminação." (SECRETARIA DE EDUCAÇÃ̆O FUNDAMENTAL, 1998,p.).

Com intuito de fortalecer o conhecimento sobre "novas" culturas, ou seja, culturas desconhecidas por diferentes populações e territórios, onde desenvolvendo estudos pode-se compreender a dinâmica atual do mundo em que vivemos, pois todas as histórias de povos heterogêneos são validas para uma compreensão enérgica do globo. Sendo assuntos de grande merecimento em eventos escolares, com ação de conhecimento, informação e a desmistificação do preconceito que atuam sobre várias culturas.

A experiência desta oficina foi obtida em primeiro momento na rede estadual de ensino, com turmas do ensino médio. $E$ em uma segunda experiência foi desenvolvida a mesma atividade em uma escola da rede municipal, em turmas do ensino fundamental II, ambas no município de Criciúma/SC. Portanto administramos a oficina para atender alunos com diferentes ritmos de aprendizagem.

Referente ao livro da Secretaria de Educação Fundamental (1998), os diferentes materiais utilizados na didática atrairia olhares críticos, gerando discussões, comparando com outras possibilidades e contextualizando de forma histórica, cultural e social. Favorecendo evidenciar valores expressados. E assim ocorreu a administração da oficina, de forma atrativa, trazendo questionamentos sobre $o$ assunto e argumentos que revelavam a curiosidade $e$ o interesse dos alunos ao assunto proposto. Como citado a oficina ocorreu com turmas de graus diferentes, havendo então uma divergência de interesses conforme as turmas participantes.

Os alunos do ensino médio se instigaram a conhecer mais sobre história e aos materiais expostos, como imagens e tecidos, que abriram 
diálogos sobre o conteúdo abordado. Onde exploraram um diferente grupo humano e absorveram a riqueza e diversidade da cultura apresentada, demonstrando respeito e a valorização com o novo conhecimento.

Os alunos do ensino fundamental mostraram maior interesse na oficina como um todo. Sendo estimuladas pela história relatada, curiosos pela informação cultural, e envolvidos na recriação da atividade exposta. Se envolvendo com maior entusiasmo dentro da oficina ofertada.

Como experiência de vivência e retorno da aplicação da oficina pode se observar, conforme cita o livro da Secretaria da Educação Fundamental (1998), que a educação não controla os fatores de formação dos alunos e não impõe os determinados valores, mas de possibilitar harmonicamente uma discussão aos alunos sobre eles, para que criassem critérios de escolha pessoal.

Com a aplicação desta oficina nós como pibidianos e futuros docentes, observamos que os professores não tem o papel de impor 0 conteúdo ao aluno, mas de instruir o aluno ao conhecimento, e despertar a curiosidade e interesse sobre o conteúdo para futuros estudos e ações com princípios morais dentro da sociedade em que se inserem.

Sendo que o conteúdo abordado na oficina não deve ser citado apenas para a memorização, mas que esteja referida permanentemente a vida dos alunos, para o entendimento da dinâmica social.

\section{CONCLUSÃO}

Pela observação dos aspectos analisados, percebemos que a realização da oficina em datas comemorativas é de grande merecimento na educação escolar. Desde que seja trabalhado de forma coerente com os conteúdos discutidos em sala de aula. A intenção da nossa oficina foi conduzir os alunos ao interesse da cultura desse povo, desmistificando o preconceito que existe sobre ela e os atraindo as belezas que existem dentro deste vasto $e$ rico continente. Sendo então que o objetivo da oficina foi alcançado de forma geral. Enriquecendo o conhecimento dos alunos, para uma melhora de sua ética pessoal e perante a sociedade. $E$ a nós bolsistas uma experiência de grande significado a uma futura docência. 


\section{REFERÊNCIAS}

CALLAI, JaemeLuiz et al. Área de Estudos Sociais: Metodologia. 2. ed. ljuí: Unijuĺ, 1986. $118 \mathrm{p}$.

PASSINI, Elza Yasuko. Prática de ensino de Geografia e estágio

supervisionado. São Paulo: Contexto, 2007. 221 p.

SECRETARIA DE EDUCAÇÃO FUNDAMENTAL. Parâmetros Curriculares

Ncionais. Brasília: Mec/sef, 1998. 436 p. 